\title{
NAÇÃO SOB PENUMBRA
}

\section{Luis Alberto Ferreira Brandão Santos*}

RESUMO:

Através do estudo de algumas imagens sugeridas pela obra de Antonio Tabucchi, este texto investiga as sombras que, segundo uma perspectiva contemporânea, interrogam a concepção bem delineada e luminosa de nação.

PALAVRAS-CHAVE: Literatura contemporânea, Nação, Identidade cultural.

$\mathrm{Na}$ nota introdutória de Noturno indiano, Antonio Tabucchi afirma que, em seu livro, procura-se uma sombra (TABUCCHI, 1991: 7). Essa procura se dá através da viagem do narrador que cruza, com seus inúmeros deslocamentos, uma paisagem desconhecida e misteriosa: a paisagem da Índia. A Índia surge como um espaço onde todas as referências - sociais, econômicas, politicas e, sobretudo, culturais e simbólicas - são imprecisas e fugidias. Buscar uma sombra, mover-se nesse espaço indefinido significa, assim, instaurar uma discussão sobre as possibilidades de delineamento de uma identidade.

No presente texto, também procuro uma sombra. Elejo também a Índia como um espaço de deslocamento, um espaço teórico para a investigação de idéias de nação. Seguindo a trilha de estudiosos como Benedict Anderson, Eric Hobsbawm e Homi Bhabha, que questionam o conceito de nação enquanto um conceito uno, homogêneo, totalizador, inserido numa visão histórica linear e contínua, me proponho a pensar a nação da perspectiva de suas margens. Investigar não apenas a luminosidade grandiloqüente que emana dos discursos que estabelecem a identidade nacional como uma essência atemporal e originária, mas também as sombras

* Doutor em Literatura Comparada, 1996. 


\section{EM TESE}

Belo Horizonte, V. I, p. I - 144, Dez. 1997

que emergem, nos interstícios da luz, quando se passa a conceber a nação exatamente como uma construção discursiva, como uma comunidade imaginada.

Entre a luz e a penumbra, inicio minha viagem, juntamente com o narrador de Noturno indiano, penetrando na paisagem dessa estranha Índia:

O ônibus atravessava uma planicie deserta e uns poucos vilarejos adormecidos. Depois de um trecho de estrada nas colinas, cheio de curvas fechadas, que o motorista tinha enfrentado com uma desenvoltura que me parecera excessiva, agora percorriamos retas enormes, tranqüilas, na silenciosa noite indiana. Tive a impressão que era uma paisagem de palmeiras e arrozais, mas a escuridão era muito profunda para dizê-lo com segurança e a luz dos faróis atravessava rapidamente 0 campo apenas durante alguma sinuosidade da estrada. (TABUCCHI, 1991: 55).

Assim como os faróis do ônibus que corta a paisagem indiana, o olhar do narrador, que conduz nosso olhar de leitor, percorre dois espaços distintos. Há um espaço iluminado, de visibilidade plena e nítida, onde a luz se difunde de modo uniforme e retilineo. Nas grandes retas, o caminho trilhado e o caminho a trithar constituem uma unidade de visão. 0 passado, o presente e o futuro da viagem se encadeiam no mesmo desenho, na mesma linha que os interliga.

Esse espaço pode ser associado à concepção tradicional de que os movimentos da História se efetuam sempre enquanto continuidade, enquanto teleologia, enquanto relação imediata e direta de causa e efeito. De acordo com essa concepção, a idéia de nação aparece imersa naquilo que Benjamin denominou de tempo homogêneo e vazio, (BENJAMIN, 1987: 229), um tempo horizontal no qual a um presente pleno corresponde uma visibilidade eterna e total do passado e uma perspectiva progressiva e progressista do futuro. Nesse tempo, o presente surge sempre como forma-mãe, em torno do qual se reúnem e se diferenciam o futuro e o passado. Passado e futuro seriam, assim, meras modificações de um presente essencial. (DERRIDA apud BHABHA, 1990: 293).

É a idéia de um tempo homogêneo e vazio que permite que a nação seja concebida, por um discurso pedagógico, enquanto uma realidade imemorial (a nação ou, pelo menos, o sentimento do nacional, sempre existiu) e eterna (a nação, como fronteira concreta ou como força simbólica, sempre existirá, projeta-se para um futuro infinito). 
Entretanto, há um outro espaço, que margeia o percurso retilíneo da luz; há uma outra paisagem, que se esquiva à visibilidade pretensamente absoluta. A penumbra vem à tona quando a linearidade do deslocamento cede espaço à sinuosidade da estrada. Nesses momentos fugidios e rápidos, fragmentos de uma outra História se iluminam. Imagens que só emergem através de lampejos, de vislumbres, exatamente porque devem sua existência à descontinuidade da visão.

A esse universo de sombras, que se recusa à totalização da plenitude da luz, corresponde uma outra temporalidade. Deslocado o historicismo, explodido o continuum da História, (BENJAMIN, 1987:230), a temporalidade aparece como uma forma disjuntiva de representação, sem uma lógica causal centrada. Passa-se a pensar a História como um conjunto de temporalidades diferenciais. Desse modo. rompe-se a pressuposição de que há um momento em que as histórias culturais se unem em um presente imediatamente legível. Nessa perspectiva, a cultura nacional se articula como uma dialética de vărias temporalidades - moderna, colonial, pós-colonial, nativa, etc. (BHABHA, 1990: 303). No esgarçamento do tempo linear, coloca-se em xeque o caráter homogêneo da nação e o discurso da coesão social moderna.

Quando se observa atentamente "a orla escura da vegetação à margem da estrada", (TABUCCHI, 1991:63), ou "o escuro da vegetação que crescia atrăs do hotel", (TABUCCHI, 1991:97), o mundo de sombras deixa entrever as características de uma outra concepção de nação. Assim como os faróis do ônibus criam um. caminho de visibilidade retilínea, a nação é uma comunidade política imaginada - imaginada não no sentido de falsa, mas de uma construção discursiva.

Assim como os farćis delimitam um campo de luz que se opõe a uma faixa de penumbra, a nação é imaginada como limitada $e$ soberana, com fronteiras finitas e bem demarcadas. Porém, as curvas do caminho provocam desvios de luz, e as fronteiras se cruzam, se indeterminam, se interpenetram.

Assim como o trajeto tranqüilo do ônibus, nas longas retas, sugere uma homogeneidade de percurso, a nação é imaginada como uma comunidade harmônica, como o exercício de um companheirismo profundo e horizonta1. (ANDERSON, 1989: 14-6). No entanto, a inevitabilidade das curvas, que introduzem na luz a 


\section{EM TESE}

Belo Horizonte, V. I, p. I - 144, Dez. 1997

descontinuidade das sombras, revela relações conflituosas. Na incongruência dos caminhos tortuosos, o linear e o sinuoso se conjugam agonisticamente.

No capítulo final de Noturno indiano, presenciamos o seguinte diálogo:

- Pensei que uma pessoa como você achasse que na vida é preciso ver o mais possivel.

- Não - ela disse convicta -, é preciso ver o menos possível. (TABUCCHI, 1991:89).

Um olhar que vê menos, que se subtrai da luminosidade preestabelecida para penetrar no universo difuso, mas sempre presente, das sombras. Talvez seja esse o olhar necessário para se observar a nação a partir de suas margens. Observar de que modo é a partir da negação das sombras que a luz impera e, simultaneamente, observar de que modo as sombras continuamente se insinuam nas minúsculas frestas da luz.

Verificar, enfim, as diversas maneiras de luz e sombras mutuamente se traduzirem. Ou ainda, de acordo com Bhabha, como se articulam o caráter pedagógico - segundo o qual os povos são apresentados enquanto objetos históricos de uma pedagogia nacionalista - e o caráter performático da nação - segundo o qual os povos se apresentam enquanto sujeitos de um processo de significação nacional. Verificar como se dá o embate entre a temporalidade contínua, acumulativa do pedagógico (o ver mais) e a estratégia recursiva, repetida, infiltradora do performático (o ver menos). (BHABHA, 1990: 297). A cultura nacional passa a ser entendida, assim, como um espaço litigioso, performático da perplexidade dos vivos no meio das representações pedagógicas da plenitude da vida. (BHABHA, 1990: 307).

Em 0 fio do horizonte, de Tabucchi, uma massa de nuvens subitamente envolve o farol e as gruas do porto, dissolvendo-os na névoa. (TABUCCHI, [s.d.]: 21). A mesma e ligeira névoa que cobre, em certos momentos, o mar e a costa. Da cidade, entretanto, essa névoa não é notada. Só é possîvel percebê-la deslocando-se até a periferia. (TABUCCHI, [s.d.]: 35). 


\section{Entre o enigma e o óbvio}

"A Índia é misteriosa por definição", (TABUCCHI, 1991:42), afirma 0 narrador de Noturno indiano. Assim, a busca do delineamento de uma identidade, pessoal e nacional, nesse espaço desconhecido que é a İndia, configura-se enquanto tentativa de resolução de um enigma. Entretanto, à medida que as pistas vão sendo seguidas, os rastros sendo trilhados, torna-se cada vez mais aguda e presente a consciência de que tal enigma é um enigma sem solução.

Também em 0 fio do horizonte, a personagem central, procurando recompor uma história obscura, tentando reconstruir um passado que assegure existência para um morto de identificação impossivel, somente pode seguir indicações precárias e levantar hipóteses não comprováveis. 0 caráter detetivesco desse empreendimento tende a patentear, exatamente, que nenhum ponto final pode ser atingido, que nenhuma verdade essencial pode ser revelada.

0 que se torna nítido é que a "arte do enigma", (TABUCCHI, 1991: 42), não é o forte desse narrador e dessa personagem. Que o mundo das sombras jamais pode ser completamente iluminado.

Da mesma forma, pode-se afirmar que o conceito de nação também é um conceito enigmático. Qualquer pista que, a princípio, parece levar a uma delimitação precisa do significado do termo nação acaba por se revelar, numa análise mais minuciosa, cercada de incertezas. Segundo Francesco Rossoli110, "o conteúdo semântico do termo, apesar de sua imensa força emocional, permanece ainda entre os mais confusos e incertos do dicionário político". (ROSSOLILLO, 1986: 795). Essas imprecisões derivam do fato de também serem imprecisas as idéias comumente arroladas como determinantes da concepção de nacionalidade.

É o caso da idéia de "laços naturais", intimamente associada à idéia de "raça". Como assinala Rossoli110, "não é preciso demorar muito para demonstrar que o termo 'raça' não possibilita a identificação de grupos que possuem limites definidos e que, de qualquer forma, as classificações 'raciais' tentadas 


\section{EM TESE}

Belo Horizonte, V. I, p. I - 144, Dez. 1997

pelos antropólogos - mediante critérios que variam para cada pesquisador ou estudioso - de maneira alguma coincidem com as Nações modernas". (ROSSOLILLO, 1986: 796).

Também é insuficiente a associação entre nação e língua, pois basta lembrar que "muitas Nações são plurilingües e muitas línguas são faladas em vărias Nações, que além disso, o monolingüismo de determinadas Nações, como a França ou a Itália, não é algo original nem espontâneo, e sim, pelo menos em parte, um fato político, fruto da imposição a todos os membros de um Estado". (ROSSOLILLO, 1986: 796). Esse caráter de imposição - que também se aplica à noção de uma homogeneidade de costumes - coloca em dúvida a concepção de uma nacionalidade espontânea, como a de Ernest Renan quando fala de uma "vontade de viver juntos", de um "plebiscito diário". (RENAN, 1990: 19).

Assim sendo, procurar desvendar o enigma que envolve o termo nação através da crença em um parâmetro fixo e absoluto significa enredar-se em outros enigmas insolúveis. Ao se lançar um facho de luz sobre uma região obscura, novas sombras se insinuam. Isso porque, como propõe Bhabha, a nação deve ser pensada enquanto narrativa, enquanto uma forma de representação da vida social. A verdade que se esconde sob o conceito de nação revela-se, fundamentalmente, como uma verdade ideológica, em que a ideologia é entendida a partir de uma concepção discursiva. Apesar de não menos concreta e atuante, uma verdade sempre mutăvel e escorregadia. Se a nação, enquanto poderosa idéia histórica, possui uma inegável força simbólica, é preciso lembrar que essa força se assenta em uma "unidade impossivel". (BHABHA, 1990: 1).

É dentro dessa perspectiva de impossibilidade de decifração de uma verdade essencial ou de revelação plena de uma identidade nacional e pessoal que se pode ler a citação, em Noturno indiano, do trecho do poema "Natal", de Fernando Pessoa. Possuindo, significativamente, alterações em relação ao texto original, significativamente traduzido, já que é recitado, em inglês, por um indiano, e apresentado na língua do narrador - 0 italiano -, o trecho citado diz: "A ciência cega lavra inúteis glebas, a fé louca vive o sonho do seu culto, um novo deus é só uma palavra, não creias nem procures: tudo é oculto". (TABUCCHI, 1991:54). 
No questionamento da pretensão de um conhecimento absoluto, seja através da racionalidade da Ciência seja através do fervor religioso da Fé, revela-se a imprecisão do próprio sentido de Verdade. Em outro trecho do mesmo poema, 1ê-se: "A Verdade nem veio nem se foi: o Erro mudou". (PESSOA, 1986: 73).

Entretanto, pelo fato de os discursos de nação se constituírem enquanto discursos pedagógicos, enquanto ideologia, o conceito de nação freqüentemente se apresenta como um conceito natural, como um conceito óbvio. Afinal, pode-se dizer, todos nós sabemos o que é uma nação. Nessa afirmativa, o caráter enigmático da nação, ou seja, a impossibilidade de se ter acesso à essência do sentido de nacional se rende à pressuposição dessa essência. Decretada a obviedade do nacional, estabelecida a crença de que tudo possui uma "evidência definitiva", (TABUCCHI, s.d.: 20), torna-se desnecessário investigar o modo como se constrói a sua significação.

Em Noturno indiano, a articulação entre luz e sombra, entre a sensação de enigma e a sensação de obviedade na percepção do espaço da Índia - e, conseqüentemente, do próprio espaço de uma identidade nacional e individual - se dá em diversos níveis.

Em alguns momentos, o que se ressalta é o sentido de exotismo da paisagem. Vivenciando um tipo de "turismo de luxo", (TABUCCHI, 1991: 87), em que a cabine do trem é "quase um aquário", (TABUCCHI, 1991: 36), o narrador pode lançar seu olhar apenas como um olhar distanciado, um olhar de fora. Através desse olhar, o que há de enigmático na paisagem reveste-se de uma luminosidade predeterminada. A Índia que se vê é a Índia que se quer ver: uma Índia opaca, uma India já vista. 0 exotismo funciona como uma operação teatral que garante a segurança de mistérios programados, que simula o enigma através de recursos óbvios, como o porteiro, no Taj Mahal, "travestido de príncipe indiano, de faixa e turbante vermelhos" e "outros empregados também fantasiados de marajá". (TABUCCHI, 1991: 31).

Entretanto, para além das "pesadas cortinas de veludo verde" que "deslizavam doces e macias como um pano de boca de um teatro", (TABUCCHI, 1991: 31), para além das luzes enganosas do exotismo, a presença incômoda e obscura dos 


\section{EM TESE}

corvos anuncia outras Indias. Com seus bicos sujos que carregam e espalham pedaços de cadáveres, os corvos "não respeitam o 'direito de admissão' vigente no Taj Mahal". (TABUCCHI, 1991: 30). Desafiando a vigilância dos polidos empregados do hotel, revelam a Índia dos problemas higiênicos, dos ratos, dos insetos, das infiltrações dos esgotos: a Índia das sombras.

Para um olhar mais atento, o que a presença insistente dos corvos sinaliza é que o Taj Mahal não é somente um hotel. É, na realidade, "uma cidade dentro da cidade". (TABUCCHI, 1991: 31). O espaço da nação passa a ser visto, dessa forma, não mais apenas como a delimitação de fronteiras externas, mas como um espaço marcado, fundamentalmente, pela "liminaridade interna". (BHABHA, 1990: 300). O caráter uno da identidade é cindido pela diferença que se instala internamente. As margens da nação não estão do lado de lá de suas fronteiras, mas no seu próprio cerne. As narrativas pedagógicas que se fundam enquanto limites totalizadores se vêem confrontadas a contranarrativas que explicitam e rasuram esses limites.

Assim, a ameaça da diferença deixa de ser apenas uma questão relativa a um outro povo (ou a uma outra identidade, a uma outra nação) e passa a ser uma questão relativa à própria "outridade" do povo-enquanto-um, (BHABHA, 1990: 301), da identidade como heterogeneidade, da nação enquanto conjunto antagônico de significações. Na paisagem óbvia, plenamente iluminada, emergem, subrepticiamente, paisagens residuais e enigmáticas. Sobre o cenário límpido do Taj Maha?, sobrevoa a sombra dos corvos.

\section{A coruja que voa no crepúsculo}

Em Noturno indiano, a percepção de que a identidade se estabelece em um espaço situado entre o narrar e o ser narrado só pôde se dar, exatamente, na Índia - esse lugar em que os homens se confundem com o pó, com meros nomes que 
se perdem na quantidade infinita de papéis de um arquivo morto. Esse lugar que exige, como adverte o médico do hospital de Bombaim, que se abandone o "luxo excessivo" das "categorias européias", (TABUCCHI, 1991:20), que se pare de conceber "o Ocidente cristão como o centro do mundo". (TABUCCHI, 1991:65).

0 que é necessário para se repensar o conceito de nação é, portanto, uma mudança de categorias. Tal mudança se efetua quando se percebe que o controle da narrativa que constitui o sentido de nacional não é monológico, quando a nação passa a ser encarada enquanto conjunto heterogêneo de significações ambivalentes.

Instalando-se a identidade enquanto jogo de narrativas, a Índia esse país feito de propósito para se perder - deixa vir à tona, sobretudo, a ambivalência particular que assombra a idéia de nação: as certezas da narrativapedagogia daqueles que escrevem e postulam a seu respeito e a perplexidade das narrativas-performances daqueles que efetivamente a vivem.

Investigar a nação a partir de sua margem implica a quebra do binarismo que opõe dentro e fora, identidade e alteridade, nacional e estrangeiro. Ao se pensar que "o 'outro' nunca está fora ou além de nós", mas que "emerge forçosamente dentro do discurso cultural", (BHABHA, 1990:1), inaugura-se uma perspectiva internacional. Ao se considerar a nação enquanto espaço de circulação de narrativas, uma perspectiva transnacional é criada.

Em certa passagem do livro, o narrador de Noturno indiano se lembra de suas antigas aulas de astronomia. Nelas, aprendeu que "quando a massa de uma estrela agonizante é superior ao dobro da massa solar, não existe mais estado de matéria capaz de deter a concentração, e esta procede ao infinito; nenhuma radiação sai mais da estrela, que se transforma assim em um buraco negro". (TABUCCHI, 1991:79).

Se no estado de adensamento absoluto as estrelas nada irradiam, desembocando em buracos negros para onde converge toda a luz, talvez seja mais interessante pensar a nação não mais como concentração de significações que se agregam ou que se anulam, mas como negociação dinâmica de sentidos. Como dispersão de sombras, divergência de significações. Como dissemiNação. 


\section{EM TESE}

Belo Horizonte, V. I, p. I - 144, Dez. 1997

Hobsbawm sugere que não é impossível se pensar no declínio do nacionalismo e do Estado-nação. A partir desse declínio, "o 'ser' inglês, ou irlandês, ou judeu, ou uma combinação desses todos" passa a ser sentido como "somente um dos modos pelos quais as pessoas descrevem suas identidades, entre muitas outras que elas usam para tal objetivo, como demandas ocasionais". (HOBSBAWM, 1991:215). O próprio fato de os historiadores estarem fazendo progressos nesse campo de estudos indica que o fenômeno já passou de seu apogeu. Nesse sentido, Hobsbawm lembra a idéia de Hegel de que a coruja de Minerva - símbolo da sabedoria - "voa no crepúsculo", e sugere que "é um bom sinal que agora está circundando ao redor das nações e do nacionalismo". (HOBSBAWM, 1991: 215).

Como um "amante de percursos incongruentes", (TABUCCHI, 1991: 7), é esse vôo e esse sinal que o leitor contemporâneo pode rastrear no universo da literatura. 
Belo Horizonte, vol. I, p. 21 - 31, dez. 1997

\section{REFERÊNCIAS BIBLIOGRÁFICAS}

ANDERSON, Benedict. Nação e consciência nacional. Trad. Lólio Lourenço de 0liveira. São Paulo: Ática, 1989.

BHABHA, Homi K. (ed.). Nation and narration. London, New York: Routledge, 1990.

BENJAMIN, Walter. Magia e técnica, arte e politica; ensaios sobre literatura e história da cultura. Trad. Sergio Paulo Rouanet. São Paulo: Brasiliense, 1987.

HOBSBAWM, Eric J. Nações e nacionalismo desde 1780; programa, mito e realidade. Trad. Maria Celia Paoli e Anna Maria Quirino. Rio de Janeiro: Paz e Terra, 1991.

PESSOA, Fernando. Obra poética. 9. ed. Rio de Janeiro: Nova Aguilar, 1986.

RENAN, Ernest. What is a nation? In: BHABHA, Homi K. (ed.). Nation and narration. London, New York: Routledge, 1990.

ROSSOLILLO, Francesco. Nação. In: BOBBIO, Norberto et al. Dicionário de política. 2. ed. Brasilia: UNB, 1986.

SANTOS, Luis Alberto Ferreira Brandão Santos. Nação: ficção - comunidades imaginadas na literatura contemporânea. Belo Horizonte: Faculdade de Letras, 1996. 208 p. (Tese, Doutorado em Literatura Comparada).

TABUCCHI, Antonio. Noturno indiano. Trad. Wander Melo Miranda. Rio de Janeiro: Rocco, 1991.

TABUCCHI, Antonio. 0 fio do horizonte. Trad. Helena Domingos. Lisboa: Difel, [s.d.]

TABUCCHI, Antonio. Pessoana mínima; escritos sobre Fernando Pessoa. Lisboa: Imprensa Nacional/Casa da Moeda, 1984. 